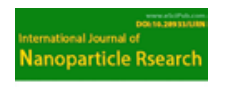

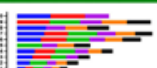

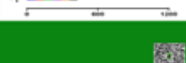

\section{International Journal of Nanoparticle Research}

(ISSN:2577-4417)

\title{
Synthesis, Characterization and Catalytic Activity of Melamine- Based Dendrimer Encapsulated Pd/Cu Bimetallic Nanoparticles
}

\author{
Md. Sayedul Islam* and Md. Wahab Khan
}

Department of Chemistry, Faculty of Engineering, Bangladesh University of Engineering and Technology (BUET), Dhaka-1000, Bangladesh

\section{ABSTRACT}

A melamine-based dendrimer was used to prepare a new class of heterogeneous $\mathrm{Pd} / \mathrm{Cu}$ bimetallic nanoparticles (NPs). The physicochemical characteristics of $\mathrm{Pd} / \mathrm{Cu}$ bimetallic NPS were studied with the aid of SEM, EDX, XRD, TG\& DSC techniques. Leafs shape surface morphology and the presence of required palladium and copper ion were observed from SEM and EDX analysis respectively while TG\& DSC showed good thermal stability, as well as XRD, revealed nano-shape FCC structure. The recycling ability of the catalyst was examined for five successive runs without any noteworthy loss of activity. The How to cite this article:

synthesized Pd/Cu bimetallic NPS exhibited high catalytic activity in the synthesis of ynone in which synthetic route was phosphine ligand-free.

Keywords: Melamine, Dendrimer, Bimetallic Nanoparticles, Ynone
*Correspondence to Author:

Md. Sayedul Islam

Department of Chemistry, Faculty of Engineering, BUET, Dhaka-1000, Bangladesh, National Science \&Technology (NST), Ph. D Fellow of ministry of Science \&Technology, Dhaka, Bangladesh

Md. Sayedul Islam and Md. Wahab Khan.Synthesis, Characterization and Catalytic Activity of MelamineBased Dendrimer Encapsulated $\mathrm{Pd} / \mathrm{Cu}$ Bimetallic Nanoparticles. International Journal of Nanoparticle Research, 2019; 2:11. DOI: 10.28933/ijonr-2019-05-2509 \section{eScîPub} eSciPub LLC, Houston, TX USA. Website: https://escipub.com/ 


\section{Introduction}

Dendrimers are highly branched, spherical, multivalent, monodisperse molecules with synthetic versatility and a broad range of implementations from catalysis to electronics and drug delivery [1-4]. Melamine-based dendritic structures usually show external groups that can take part in bonding with hydrogen. Fréchet and coworker illustrated in an elegant example the self-assembly of greaterordered dendrimer structures by adding two complementary hydrogen-bonding moieties to the focal point of various dendrons $[5,6]$.

Moreover, bimetallic nanoparticles, consisting of two different metals, display enhanced catalytic output and implementations in so many industrial applications, predominantly in fuel industries or environmental catalytic processes, and lately in $\mathrm{C}-\mathrm{C}$ cross-coupling reactions [7]. Bimetallic catalysts constitute a remarkable class of catalysts as a result of which one metal can modify and/or alter catalytic properties of the other owing to the electronic and structural interactions [8].

Furthermore, they are effective due to the adjustment of their surface electrons comparative to that of individual metals $[9,10]$. The composition, framework and more exploitation of catalytic activity of bimetallic particles were shown to be of tremendous interest [11, 12]. It has been demonstrated that metals interacting with either another metal or metal compound at the nano level can shape nanoparticles with greater activities not found in bulk alloys [13].

On the other hand, numerous metal-catalyzed cross-coupling reactions involve either another metal to be present as a co-catalyst to support the entire process. Sonogashira reaction between an aryl halide and terminal alkynes requires a lot of $\mathrm{Pd}$ and $\mathrm{Cu}$ as a catalyst in which $\mathrm{Cu}+$ plays a catalytic role in switching the alkynyl group to Pd [14].

In addition, the outstanding redox characteristics of the $\mathrm{Pd} / \mathrm{Cu}$ system are due respectively to the electron donor and acceptor character of $\mathrm{Cu}$ and $\mathrm{Pd}[15,16]$. The noticeable "Cu-effect" in the Pdcatalyzed cross-coupling reaction induced the progression of many heterogeneous bimetallic NPs utilizing available in the market insoluble polymeric supports and has been used satisfactorily in numerous cross-couplings [17, 18].

However, bimetallic nanoparticles catalysts inserted in/on insoluble supports with ligand-free and negligible or no leaching are extremely desirable from the perspective of decreasing environmental burdens as well as costeffectiveness. The major challenges for a heterogeneous catalyst remain procedural brevity, uniform dispersion, lower cost and reliable dendrimeric surface, better efficiency and life cycle.

Yet, to the best of our knowledge, there is no study obtainable in the literature on the synthesis of bimetallic NPs encapsulated with melamine based dendrimer and the utilization in crosscoupling reaction such as ynone preparation reactions of their heterogeneous catalytic activity. Here, we have reported the synthesis, characterization, and utilization as a catalyst in the synthesis of biologically and pharmaceutically important intermediates ynone compound of a new class of heterogeneous melamine based dendrimer encapsulated $\mathrm{Pd} /$ Cu bimetallic NPs.

\section{Experimental}

\section{Materials and Methods}

All the solvents such as DMF, DMSO, $\mathrm{CH}_{3} \mathrm{CN}$, $\mathrm{C}_{2} \mathrm{H}_{5} \mathrm{OH}$, DMF, and bases, for example, $\mathrm{NaOH}$, $\mathrm{KOH}, \mathrm{KO} B \mathrm{Bu}, \mathrm{Na}_{2} \mathrm{CO}_{3}$, and $\mathrm{Et}_{3} \mathrm{~N}$, all the reagents such as melamine, Anisoyl chloride, 1-heptyne, $\mathrm{CuCl}_{2} .2 \mathrm{H}_{2} \mathrm{O}$, and $\mathrm{PdCl}_{2}$ were purchased from Aldrich and were directly used without further purification. The IR spectra were taken on a Shimadzu FTIR 8400S Fourier Transform with $\mathrm{KBr}$ pellets. NMR spectra were taken using tetramethylsilane as an internal standard on the BRUKER DPX-400 spectrophotometer. Analytical thin layer chromatography (TLC) was 
Md. Sayedul Islam and Md. Wahab Khan, IJNR, 2019; x:xx

silica gel $60 \mathrm{~F} 254$ coated on 25 TCC aluminum sheets $(20 \times 20 \mathrm{~cm})$. Silica gel column chromatographic separations were made on silica gel $60 \mathrm{~N}$ (neutral, 40-100 $\mu \mathrm{M}$ ). The thermal stability of nanoparticles was ascertained by a thermogravimetric analyzer (NETZSCH STA 449F3) from 26 to $600{ }^{\circ} \mathrm{C}$. TG and DSC data were observed under a nitrogen atmosphere by using aluminum oxide crucible at a heating rate of $10 \mathrm{k} / \mathrm{min}$ and at a flow rate of 40 and 60 $\mathrm{mL} / \mathrm{min}$. SEM and EDX of Pd/Cu bimetallic NPs 4 were taken by the JEOL-JSM-7600F. Particle size and phase were identified with a PANANALYTICAL x-ray diffractometer. Elemental analyses were carried out with a Fisons EA 1108 CHNS-O apparatus. Particle size and phase identification were performed with a PANANALYTICAL $x$-ray diffractometer. The leaching study was done by Perkin Elmer ELAN DRC E ICP/MS.

\section{Synthesis of 2,4,6-tris(di-4-methoxybenzamido)}

\section{-1,3,5-triazine 3}

$0.492 \mathrm{~g}(0.0039 \mathrm{~mol})$ of melamine was dissolved in $10 \mathrm{ml}$ of dimethylsulfoxide (DMSO) in a $250 \mathrm{ml}$ round bottle flask and then $2.16 \mathrm{~g}(0.024 \mathrm{~mol})$ of anisoyl chloride was added to it. The reaction mixture was allowed to stir with reflux at $90{ }^{\circ} \mathrm{C}$ temperature for 8 hours. Reaction advancement was monitored with TLC. After completion of the reaction, the flask was allowed to cool at room temperature and some pieces of ice were poured in the flask very carefully. After a while, it was filtered on a Buchner funnel and washed with Sodium bicarbonate solution to remove completely any remaining acid. Finally, the compound was purified by recrystallization with ethanol.

White crystalline solid; yield: $94 \%$, IR (KBr): $v_{\max }$ $=3015.00,1765.21,1615.50,1415.20,1290.40$ $\mathrm{cm}^{-1} .{ }^{1} \mathrm{H}$ NMR $\left(400 \mathrm{MHz}, \mathrm{CD}_{3} \mathrm{OD}\right): \delta=6.87(\mathrm{~d}$, $12 \mathrm{H}, \mathrm{J}=8.8 \mathrm{~Hz}$ ), $7.73(\mathrm{~d}, 12 \mathrm{H}, \mathrm{J}=9.2 \mathrm{~Hz}), 3.72$, (s, 18H) ppm. ${ }^{13} \mathrm{C}$ NMR $\left(100 \mathrm{MHz}, \mathrm{CD}_{3} \mathrm{OD}\right): \delta=$ 169.99, 144.97, 130.80, 130.09, 129.10, 21.58 ppm. Anal. Calcd. for $\mathrm{C}_{51} \mathrm{H}_{42} \mathrm{~N}_{6} \mathrm{O}_{12} ; \mathrm{C} 65.80, \mathrm{H}$ 4.55, N 9.03; found: C 65.70, H 4.45, N 9.00
Synthesis of melamine Based Dendrimer Encapsulated Pd/Cu Bimetallic NPs 4

0.100 g 2,4,6-tris(di-4-methoxy benzamido)1,3,5-triazine $3(0.12 \mathrm{mmol}), 0.00096 \mathrm{~g} \mathrm{PdCl}_{2}$, $\mathrm{NH}_{2}-\mathrm{NH}_{2} . \mathrm{H}_{2} \mathrm{O}(1.5 \mathrm{mmol})$ were stirred in $\mathrm{CH}_{3} \mathrm{CN}$ $(10 \mathrm{~mL})$ in a round bottom flask at $90{ }^{\circ} \mathrm{C}$ for 1 hour under reflux condition. Then $0.01536 \mathrm{~g}$ of $\mathrm{CuCl}_{2} .2 \mathrm{H}_{2} \mathrm{O}(\mathrm{Pd} / \mathrm{Cu}$ weight ratio of $1: 16)$ and $\mathrm{NH}_{2}-\mathrm{NH}_{2} \cdot \mathrm{H}_{2} \mathrm{O}$ were added drop wise to some extent in excess of the equivalent amount of copper salt to the reaction mixture. The $\mathrm{NaOH}$ solution $(0.3 \mathrm{M})$ was gradually added to the reaction mixture in order to maintain $\mathrm{pH} 12$ and the suspension was robustly stirred at $90^{\circ} \mathrm{C}$ for 2 hrs with a magnetic stirring bar. The black residue was originated after the reaction mixture had been settled down. The residue was filtered after the reaction mixture was centrifuged (4000 rpm for $20 \mathrm{~min}$ ), washed with distilled water and acetone and dried overnight at $130{ }^{\circ} \mathrm{C}$ in an oven.

\section{Application of $\mathrm{Pd} / \mathrm{Cu}$ bimetallic NPs 4 as a catalyst in the synthesis of ynone}

Synthesis of 1-phenyloct-2-yn-1-one 7

In $\mathrm{C}_{2} \mathrm{H}_{5} \mathrm{OH}(10 \mathrm{~mL})$ a combination of benzoyl chloride $5(1.0 \mathrm{mmol})$ with 1-Heptyne $6(1.2$ $\mathrm{mmol}), \mathrm{Pd} / \mathrm{Cu}$ bimetallic NPs 4 (1.5 mol \%) and triethylamine $(1.2 \mathrm{mmol})$ were stirred for 30 minutes in a round bottom flask in a nitrogen atmosphere at $70{ }^{\circ} \mathrm{C}$. The advancement of the reaction was monitored by TLC. The reaction mixture was evaporated under reduced pressure to dryness at the end of the reaction and the residue was eliminated with chloroform. Washed with distilled water, the chloroform extract was dried over anhydrous $\mathrm{MgSO}_{4}$, filtered and concentrated under reduced pressure. Then it was purified with $\mathrm{n}$-hexane/chloroform (8:1) through silica gel column chromatography. Solid white product was obtained, yield \% 90; mp. 70$72^{\circ} \mathrm{C}$, IR (KBr): $v_{\max }=3312.85,2975.30$, 2938.65, 2739.97, 2492.11, 2357.09, 2162.09, 1474.63, 1398.64, $1171.79 \mathrm{~cm}^{-1} ;{ }^{1} \mathrm{H}-\mathrm{NMR}$ $\left(\mathrm{CDCl}_{3}, 400 \mathrm{MHz}\right): \delta 7.45$ (d, $\left.J=8.0,2 \mathrm{H}\right) ; 7.11$ (t, $J=8.0,2 \mathrm{H}) ; 6.37-6.44(\mathrm{~m}, 3 \mathrm{H}) ; 2.42$ (t, $J=8.0$, $2 \mathrm{H}) ; 1.92-1.90(\mathrm{~m}, 2 \mathrm{H}) ; 1.44-1.37(\mathrm{~m}, 4 \mathrm{H}) ; 0.93$

IJNR: https://escipub.com/international-journal-of-nanoparticle-research/ 3 
(t, J=7.6, 3H). ${ }^{13} \mathrm{C}-\mathrm{NMR}\left(\mathrm{CDCl}_{3}, 400 \mathrm{MHz}\right): \delta \quad$ nitrogen atmosphere (Scheme 1). The growth of $175.28,135.11,134.23,130.13,129.23,94.33$, the reaction was monitored by thin layer 30.09, 28.27, 18.90, 14.44

\section{Results and Discussion}

\section{Synthesis and characterization}

Dendrimer 3 was produced by the reaction of $0.492 \mathrm{~g}(0.0039 \mathrm{~mol})$ of melamine 1 with $2.16 \mathrm{~g}$ $(0.024 \mathrm{~mol})$ of anisoyl chloride in anhydrous DMSO at $90{ }^{\circ} \mathrm{C}$ temperature for 8 hours under a chromatography (TLC) and after the completion of the reaction, the solid reaction mixture was washed with sodium bicarbonate solution and recrystallized with ethanol that gave the dendrimerized product 3 . The product was analyzed by using IR, ${ }^{1} \mathrm{H}$ NMR, ${ }^{13} \mathrm{C}$ NMR (S1-S3 in the supporting information).
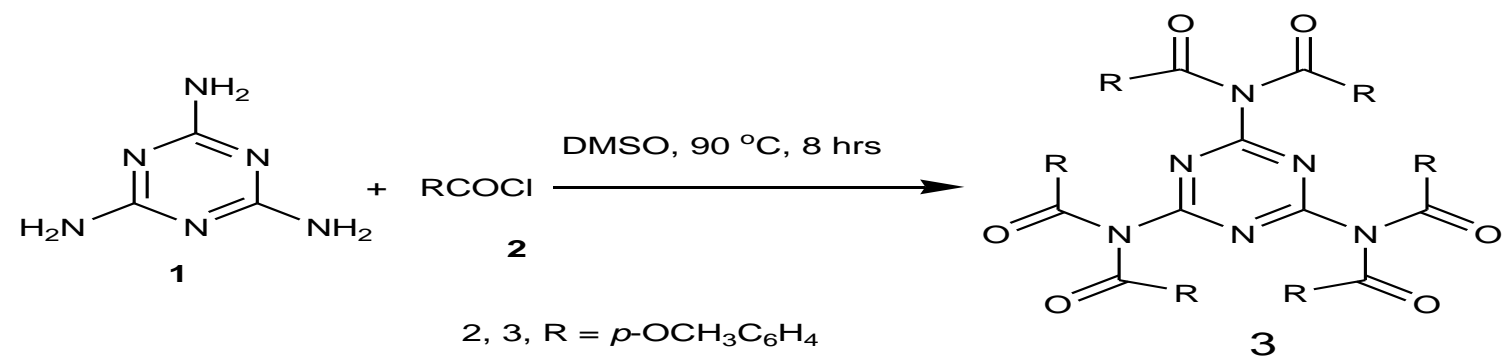

In the IR spectrum the presence of vital peaks confirmed the structure of compound 3 . The peak at the stretching bands 3015, 2965 and $1510 \mathrm{~cm}^{-1}$ indicated the existence of aromatic $\mathrm{C}-\mathrm{H}$, aliphatic $\mathrm{C}-\mathrm{H}$ and aromatic $\mathrm{C}=\mathrm{C}$ respectively whereas the band was originated at $1680-1770 \mathrm{~cm}^{-1}$ due to $\mathrm{C}=\mathrm{O}$ groups. Here it is

noteworthy that there's no band for $\mathrm{N}-\mathrm{H}$ near about $3400-3200 \mathrm{~cm}^{-1}$ which was proved that $1^{\circ}$ amino group of melamine was changed into $3^{\circ}$ amido group. In ${ }^{\mathrm{H}} \mathrm{NMR}$ and ${ }^{13} \mathrm{C}$ NMR spectra offered the preferred dendrimer 3 . There is no ${ }^{1} \mathrm{H}$ NMR peak for $\mathrm{NH}$ or $\mathrm{NH}_{2}$ group, which was additional established the structure of 3 .
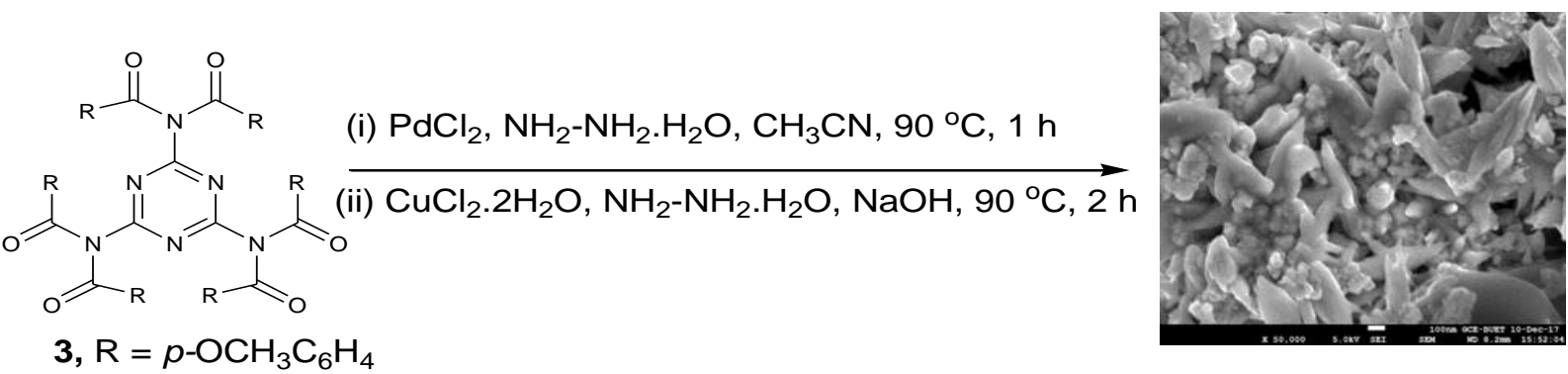

$\mathrm{Pd} / \mathrm{Cu}$ bimetallic NPs, 4

\section{Scheme 2. Synthesis of $\mathrm{Pd} / \mathrm{Cu}$ bimetallic NP 4}

The melamine-based dendrimer supported $\mathrm{Pd} /$ $\mathrm{Cu}$ bimetallic NPs4 was produced by using a sequential loading approach (Scheme 2) and thus described with various physicochemical techniques including SEM, EDX, XRD, TGA, and DSC. The dendritic globular or leaf shape was shown in the SEM images of Pd$\mathrm{Cu}$ bimetallic NP 4 (Figure 1). The presence of copper was $60.75 \%$ of the mass and palladium $4.40 \%$ of the mass of the synthesized NPs (Figure 2) was identified by EDX analysis Furthermore, the EDX results confirmed that the sequential loading technique might be quite successful in preparation the melamine baseddendrimer template $\mathrm{Pd} / \mathrm{Cu}$ bimetallic nanoparticle 4. 

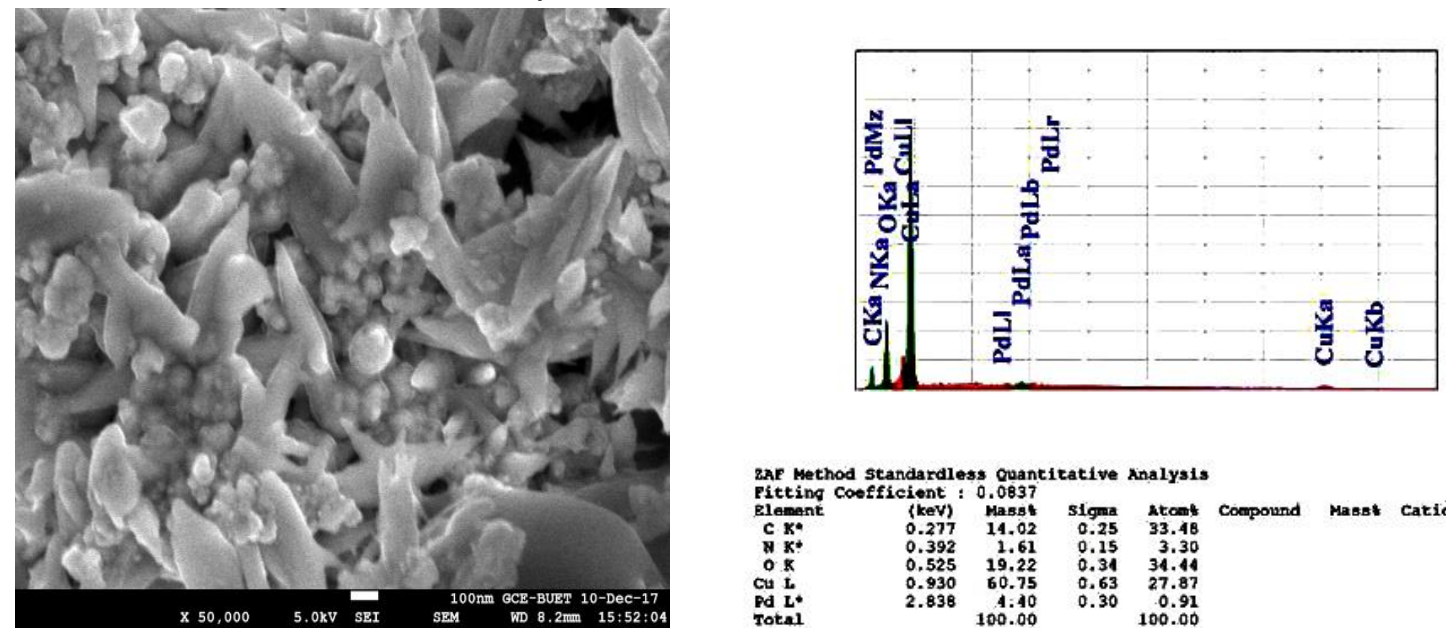

Aequisition Parameter Instrument : 7600 F Probe current: $10.00000 \mathrm{nt}$

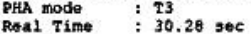
Rive Time $\quad 30.28 \mathrm{sec}$

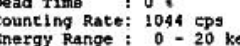

Figure $1 \mathrm{SEM}$ of Pd/Cu bimetallic NPs 4 . Figure 2 of EDX of Pd/Cu bimetallic NPs 4.

The particle structures of Pd-Cu bimetallic NPs 4 was additional described by the XRD patterns (Figure 3). The peaks at 2theta(o) values of 52.70 and 73.40 degrees relate to (200) and (220) copper planes respectively those directed for the creation of FCC copper nanoparticles and associated with the JCPDS General Powder Diffraction Card, Copper Record No (04-0836) [17] while the peaks at 2theta(o) values of 39.10 , 55.00 and 67.30 correspond to (111), (200) and (220) planes of Palladium respectively those regarded as the formation of FCC Palladium nanoparticle and Palladium report no (461043) [18], (figure 3), compared to the wellknown JCPDS powder diffraction card. As a result, these results were revealed in $\mathrm{Pd}-\mathrm{Cu}$ bimetallic NP's FCC structure. The Pd-Cu bimetallic NP 4 XRD pattern shows the average $18.60 \mathrm{~nm}$ particle length calculated through the Debye-Scherrer formula.

. Thermal steadiness is the main characteristic for catalysts to maintain their activity in long reaction times. It was detected from the $T G$ and DSC curves of the $\mathrm{Pd} / \mathrm{Cu}$ bimetallic NP 4 (Figure 3). The material of nanoparticle changes with its structure and composition and is measured through the thermo-gravimetric diagram depending on the weight loss of these elements.

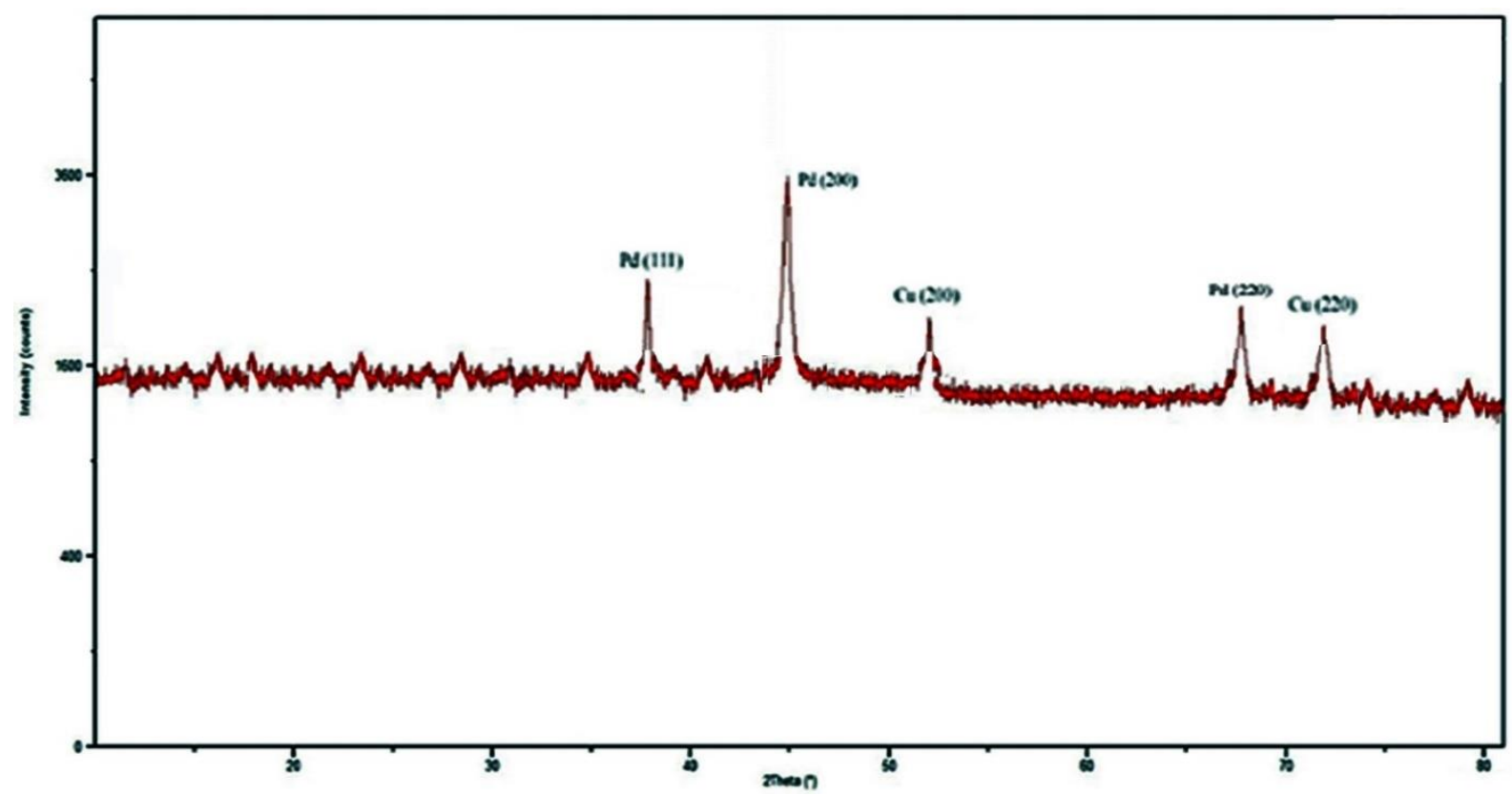

Figure 3 XRD pattern of Pd-Cu bimetallic NPs 4 
From the TG curve, it was recorded that the overall weight loss of compound 4 from $330^{\circ} \mathrm{C}$ to $395{ }^{\circ} \mathrm{C}$ and the DSC values are just about comparable to the TG values. The melting point was indicated at approximately $330^{\circ} \mathrm{C}$ from the DSC endothermic curve. The final step of decay revealed about $19.10 \%$ ash residue of the catalyst 4 .

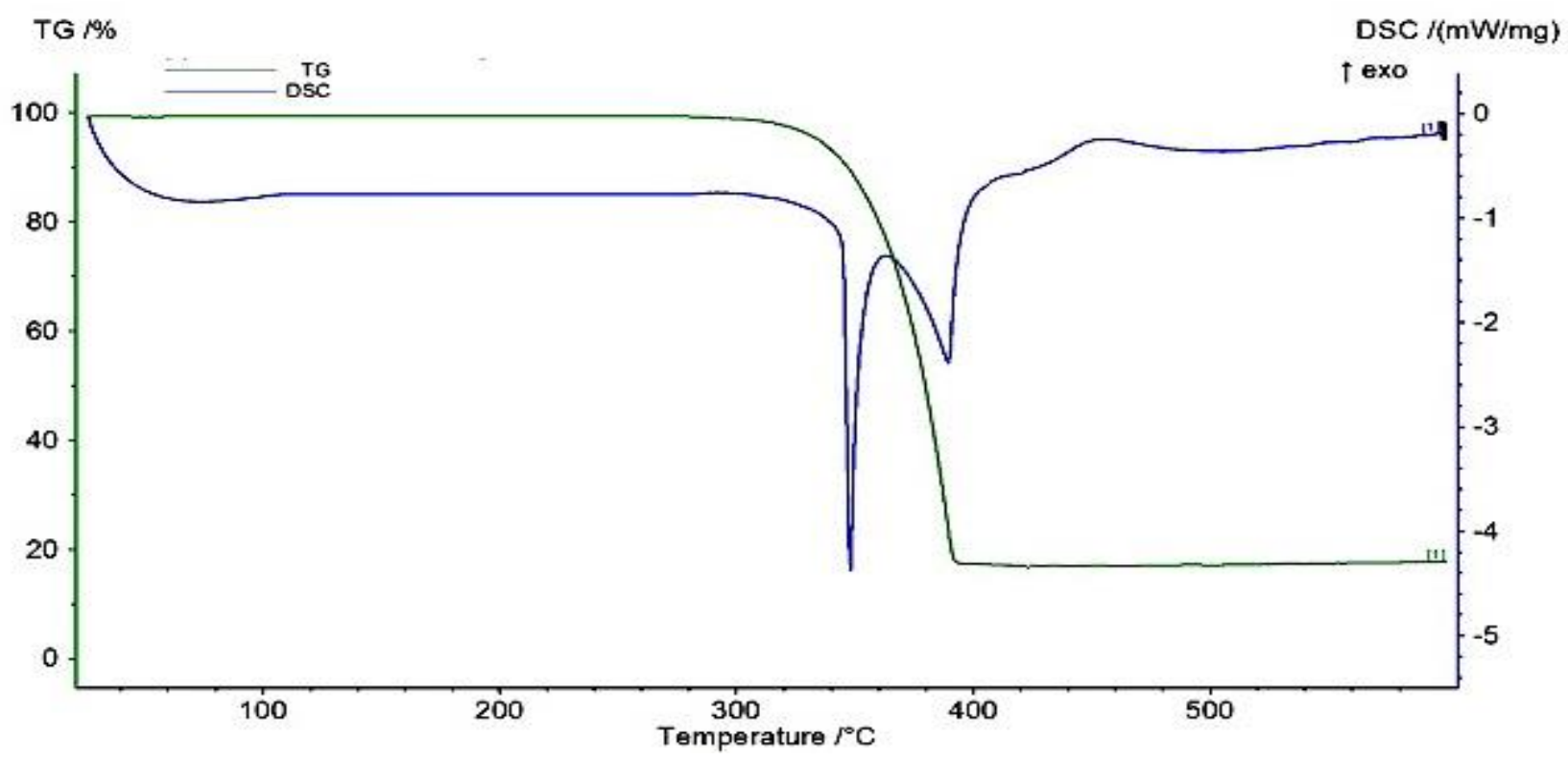

Figure 4. TG\& DSC curves of Pd-Cu bimetallic NPs 4

\section{Catalytic performance}

The catalytic effect for the melaminebased dendrimer containing $\mathrm{Pd} / \mathrm{Cu}$ bimetallic NPs 4 through the reaction between acyl chlorides with a terminal alkyne. Using $\mathrm{Pd} / \mathrm{Cu}$ bimetallic NPs 4 (Scheme 3), the reaction between benzoyl chloride and 1-Heptyne was chosen to optimize the synthetic method of ynone. The cross-coupling reaction was performed at $70{ }^{\circ} \mathrm{C}$ with the presence of $\mathrm{NaOH}$ as a base and DMF as a solvent to produce 20 $\%$ yield for the catalyst $\mathrm{Pd} / \mathrm{Cu}$ bimetallic NPs 4 (entry 1). We elected another four bases for $\mathrm{KOH}, \mathrm{KO} B \mathrm{Bu}, \mathrm{Na}_{2} \mathrm{CO}_{3}$, and $\mathrm{Et}_{3} \mathrm{~N}$ (Table 1, entries 2-4) and noticed that $\mathrm{Et}_{3} \mathrm{~N}$ was the best base for this reaction. The solvent effect was also examined by using $\mathrm{H}_{2} \mathrm{O}$, DMF, toluene and acetonitrile and ethanol and also ethanol was found as a best solvent. The optimized reaction condition was indeed found when $1.5 \mathrm{~mol} \%$ of $\mathrm{Pd} / \mathrm{Cu}$ bimetallic NPs 4 and $\mathrm{Et}_{3} \mathrm{~N}$ and $\mathrm{C}_{2} \mathrm{H}_{5} \mathrm{OH}$ were used at $70^{\circ} \mathrm{C}$ (Table 1, Entry 5) under the nitrogen atmosphere. The product 7 was analyzed by IR, ${ }^{1} \mathrm{HNMR},{ }^{13} \mathrm{CNMR}$ (Figures $4-6$ in the supporting information).

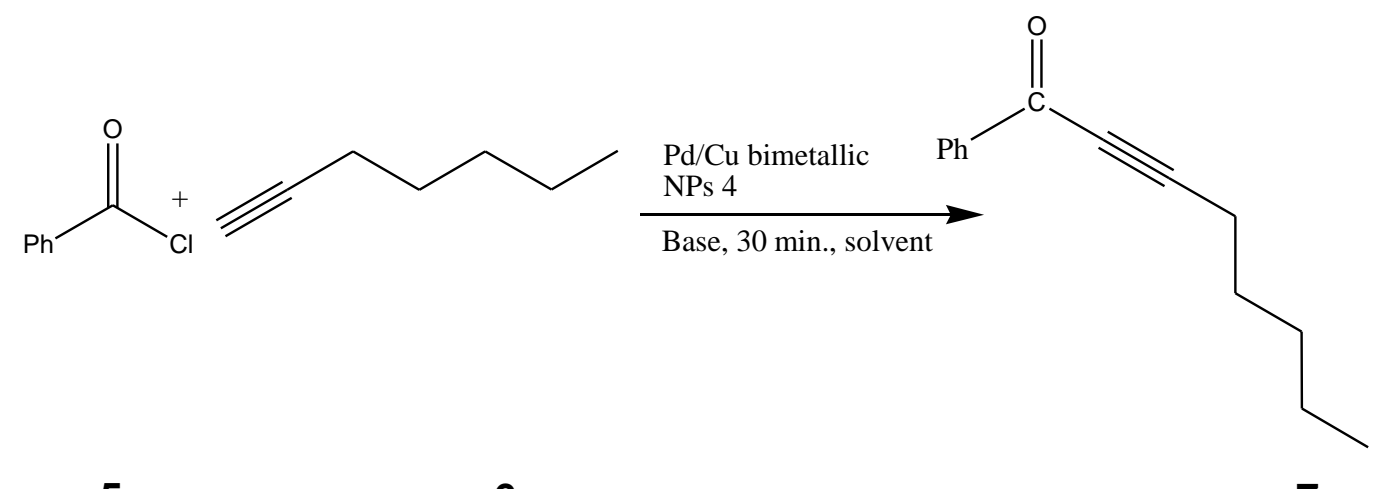

\section{Scheme 3}


Table 1. Reaction condition optimization for the coupling reaction of benzoyl chloride with 1heptyne catalyzed by Pd/Cu bimetallic NPs 4

\begin{tabular}{|l|l|l|l|l|l|}
\hline Entry & Base & Temp $\left({ }^{\circ} \mathrm{C}\right)$ & solvent & Catalyst, 4 (mol\%) & Yield $(\%)$ \\
\hline 1 & $\mathrm{NaOH}$ & 70 & DMF & 1.5 & 20 \\
\hline 2 & $\mathrm{KOH}$ & 80 & Toluene & 1.0 & 10 \\
\hline 3 & $\mathrm{KO}{ }^{t} \mathrm{Bu}$ & R.T. & $\mathrm{CH}_{3} \mathrm{CN}$ & 1.0 & N. R \\
\hline 4 & $\mathrm{Na}_{2} \mathrm{CO}_{3}$ & 80 & $\mathrm{H}_{2} \mathrm{O}$ & 1.5 & 40 \\
\hline 5 & $\mathrm{Et}_{3} \mathrm{~N}$ & 70 & $\mathrm{C}_{2} \mathrm{H}_{5} \mathrm{OH}$ & 1.5 & 90 \\
\hline
\end{tabular}

Reaction conditions: benzoyl chloride $(1 \mathrm{mmol}), 1$-heptyne $(1.2 \mathrm{mmol})$, base $(1.2 \mathrm{mmol})$, time-30 min, solvent $(10 \mathrm{~mL})$, b) Yield \% of products is based on benzoyl chloride.

\section{Test for Recyclability}

The reusability of the catalyst 4 was examined in the reaction between benzoyl chloride and 1 heptyne. After every catalytic run, the catalyst 4 was recovered from the reaction mixture by simple filtration, washed with water followed by acetone, and then dried under vacuum. The recovered catalyst was reused five times without noteworthy losing its catalytic activity (Table 2 ).

SEM images of the recovered Pd-Cu bimetallic NPs 4 showed nearly retained surface morphology of original catalyst (Fig. 5) as well as $\mathrm{Pd}(4.00 \%$ of mass) and $\mathrm{Cu}(59.05 \%$ of mass $)$ were found from EDX analysis (Fig. 6)

Table 2- Recyclability of Pd-Cu bimetallic NPs 4 of the coupling reaction between benzoyl chloride and 1-heptyne.

\begin{tabular}{|l|l|l|l|}
\hline Entry & Run & Time $(\mathrm{h})$ & Yield \% \\
\hline 1 & Fresh & 0.5 & 90 \\
\hline 2 & 1 & 0.5 & 88 \\
\hline 3 & 2 & 0.5 & 86 \\
\hline 4 & 3 & 0.5 & 82 \\
\hline 5 & 4 & 0.5 & 80 \\
\hline
\end{tabular}

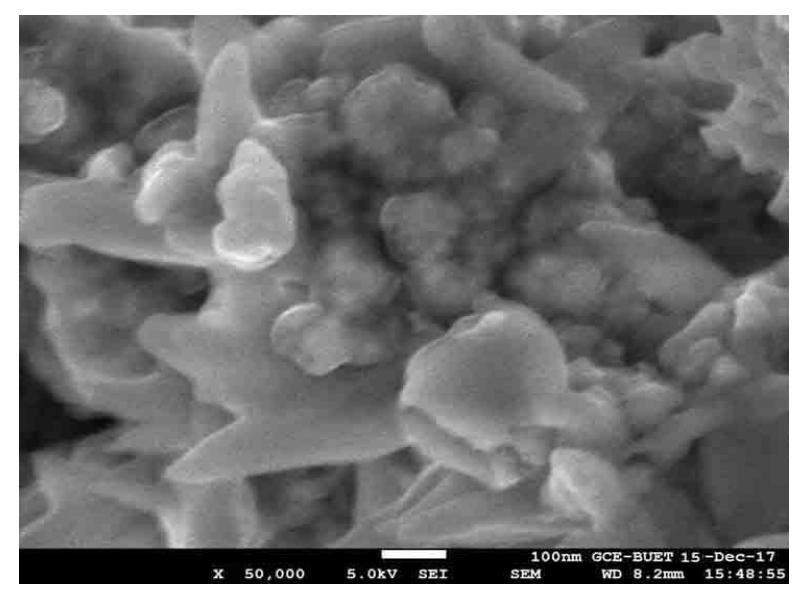

Figure 5 SEM image of the recovered NP 4

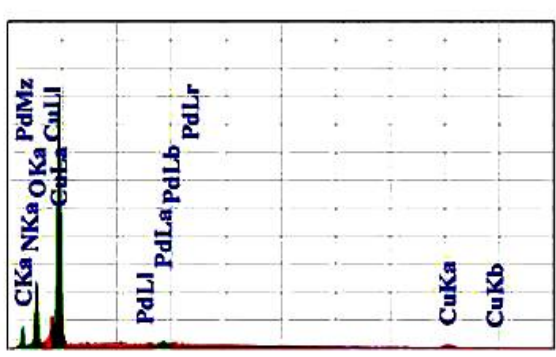

Aequisition Parameter $\begin{array}{ll}\text { Instrument }: & 7600 \mathrm{~F} \\ \text { Acc. Volcage } & 10.0 \mathrm{KV}\end{array}$ Prabe curgent: 1.00000 Ratil Time $: 30.28 \mathrm{sec}$ Dead Time : 01
Councing Rate: 1044 cps
Energy Range : $0-20$ ke Energy Range: : $04-20 \mathrm{ket}$ 
Md. Sayedul Islam and Md. Wahab Khan, IJNR, 2019; x:xx

In addition, the catalyst's leaching study was performed due to checking heterogeneity. The reaction mixture was analyzed by ICP-MS after isolation of the catalyst and only $0.20 \mathrm{ppm}$ of copper was observed in the reaction mixture. All the results showed that our catalyst was almost similar before the catalyst showed high stability and reusability.

\section{Conclusion}

In overview, we have synthesized heterogeneous Palladium-Copper bimetallic nanoparticles by sequential loading method templated by melamine-based dendrimer. Because of the low cost of melamine but still, most effective palladium with bimetallic nanocatalyst and therefore due to make a potentially valuable, recoverable, reusable $\mathrm{Pd} / \mathrm{Cu}$ bimetallic nanocatalyst, a small quantity of palladium salt were used with a copper salt. All evaluative results (SEM, EDX, XRD, TG \& DSC) verify their heterogeneous catalytic activity in the carbon-carbon cross-coupling reaction such as Sonogashira type reaction of the synthesis of ynone and the synthetic path was also observed to be phosphine-ligand free. Additional applications of this heterogeneous catalytic activity in numerous $\mathrm{C}-\mathrm{C}$ coupling reactions is now under-investigated.

\section{Acknowledgments:}

We thank the Ministry of Science and Technology, Dhaka, Bangladesh (National Science and Technology Fellowship Program 2018-2019, Ph.D. Fellowship, No39.00.0000.012.002.03. 8.25, Code No1260101-120005100-3821117) for providing financial support for our research work.

Conflicts of Interest: The authors confirm no conflicts of interest.

\section{References}

1. Wang $\mathrm{D}$, Li Y. Bimetallic nanocrystals: liquidphase synthesis and catalytic applications. Adv Mater (2011); 23(9):1044-60.

2. Aulenta F, Hayes W and Rannard S. Dendrimers: a new class of nanoscopic containers and delivery devices. Euro Polym J (2003); 39(9): 1741-1771.
3. Greish K, Fang J, Inutsuka T, Nagamitsu A. and Maeda H. Macromolecular therapeutics. Clinical pharmacokinetics (2003); 42(13): 1089-1105.

4. Gupta U, Agashe H B, Asthana A. and Jain N K. Dendrimers: novel polymeric nanoarchitectures for solubility enhancement. Biomacromolecules (2006); 7(3): 649-658.

5. Liu M and Fréchet $\mathrm{J} \mathrm{M}$, Designing dendrimers for drug delivery. Pharm sci \& techno today (1999); 2(10): 393-401.

6. Dahlous K, Almarhoon Z, Badjah-Hadj-Ahmed, A $Y, A L$ Othman $Z$ and El-Faham A. Microwave Irradiation Assists the Synthesis of a Novel Series of bis-Arm s-Triazine Oxy-Schiff Base and Oxybenzylidene Barbiturate Derivatives. Molecules (2018); 23(11): 2976.

7. Fréchet J.M. Dendrimers and supramolecular chemistry. Proceedings of the National Academy of Sciences (2002); 99(8): 4782-4787.

8. Pérez-Temprano $\mathrm{M} \mathrm{H}$, Casares $\mathrm{J} \mathrm{A}$ and Espinet P. Bimetallic Catalysis using Transition and Group 11 Metals: An Emerging Tool for C C Coupling and Other Reactions. Chem-A Euro J (2012); 18(7): 1864-1884.

9. Coq B and Figueras F. Bimetallic palladium catalysts: influence of the co-metal on the catalyst performance. J Molec Catal A: Chem (2001); 173(1-2): 117-134.

10. Han S W, Kim Y and Kim K. Dodecanethiolderivatized Au/Ag bimetallic nanoparticles: TEM, UV/VIS, XPS, and FTIR analysis. J collid Interf Sci (1998); 208(1): 272-278.

11. Link S, Wang $Z$ L and El-Sayed M A, Alloy formation of gold- silver nanoparticles and the dependence of the plasmon absorption on their composition. J Phy Chem B (1999); 103(18): 3529-3533.

12. Sinfelt J H and Cusumano J A Bimetallic catalysts. Exxon monograph. Wiley, New (1983) 44.

13. Sinfelt J H. Ruthenium-copper: a model bimetallic system for studies of surface chemistry and catalysis. Int Rev Phys Chem (1988); 7(4): 281315.

14. Rodriguez J. Physical and chemical properties of bimetallic surfaces. Surf Sci Rep (1996); 24(7-8): 223-287.

15. Chinchilla R and Nájera $C$. The Sonogashira reaction: a booming methodology in synthetic organic chemistry. Chem Rev (2007); 107(3): 874-922.

16. Allred G D and Liebeskind L S. Copper-mediated cross-coupling of organostannanes with organic iodides at or below room temperature. $J$ Am Chem Soc (1996); 118(11): 2748-2749. 
Md. Sayedul Islam and Md. Wahab Khan, IJNR, 2019; x:xx

17. Shih $Z Y$, Wang $C W, X u G$ and Chang $H T$. Porous palladium copper nanoparticles for the electrocatalytic oxidation of methanol in direct methanol fuel cells. J Mater Chem A (2013); 1(15): 4773-4778.

18. Myers S V, Frenkel A I and Crooks R M. X-ray absorption study of $\mathrm{PdCu}$ bimetallic alloy nanoparticles containing an average of $\sim 64$ atoms. Chem Mater (2009); 21(20): 4824-4829.

19. Sengupta D, Saha J, De G and Basu B. Pd/Cu bimetallic nanoparticles embedded in macroporous ion-exchange resins: an excellent heterogeneous catalyst for the Sonogashira reaction. J Mater Chem A (2014); 2(11): 39863992.

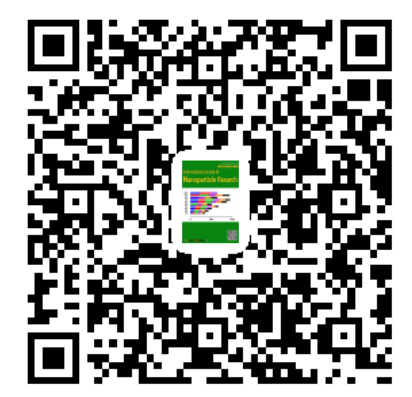


Supporting Information

IR spectra of 2,4,6-tris(di-4-methoxybenzamido)-1,3,5-triazine 3

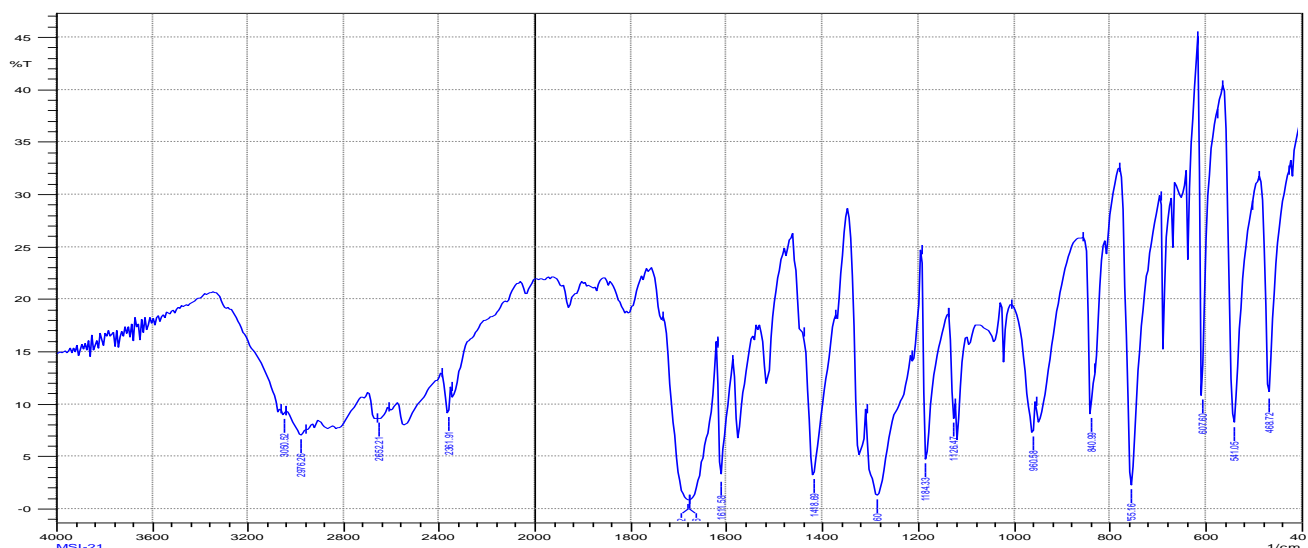

Figure. S1 IR spectra of 2,4,6-tris(di-4-methoxybenzamido)-1,3,5-triazine 3

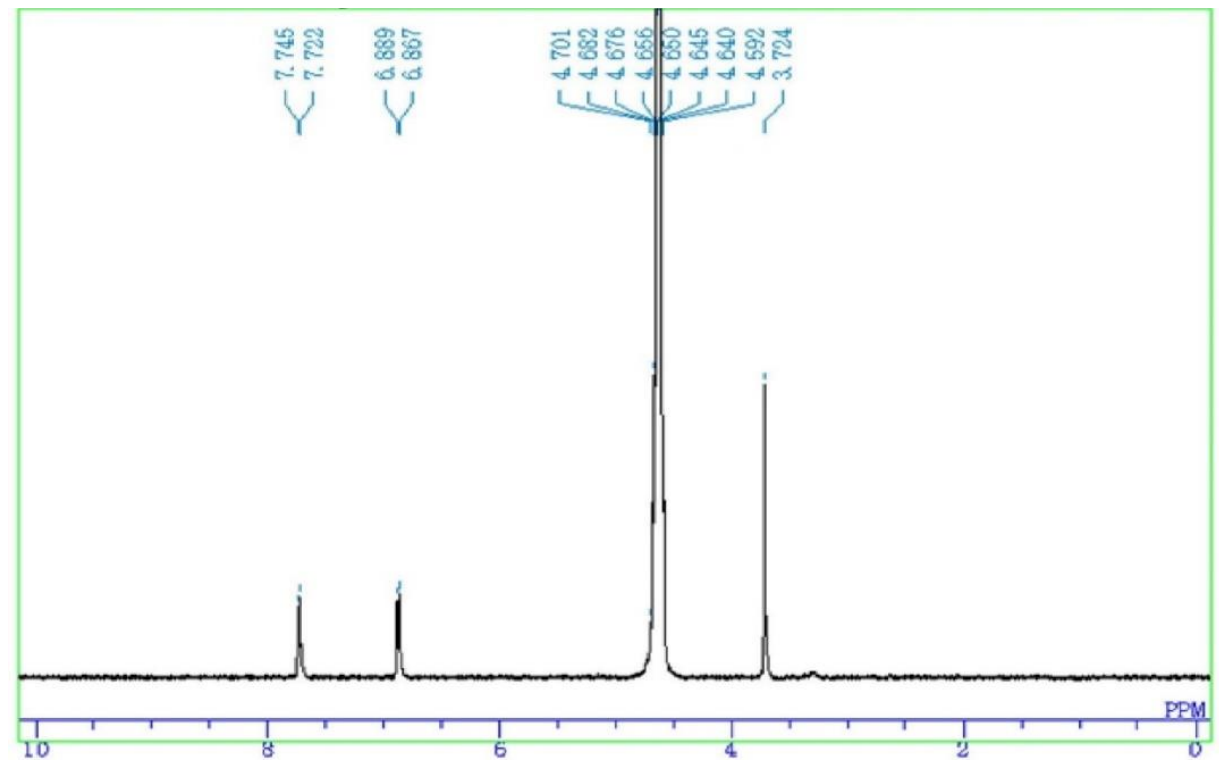

Fig. S2 ${ }^{1} \mathrm{H}$ NMR spectrum of the compound 3

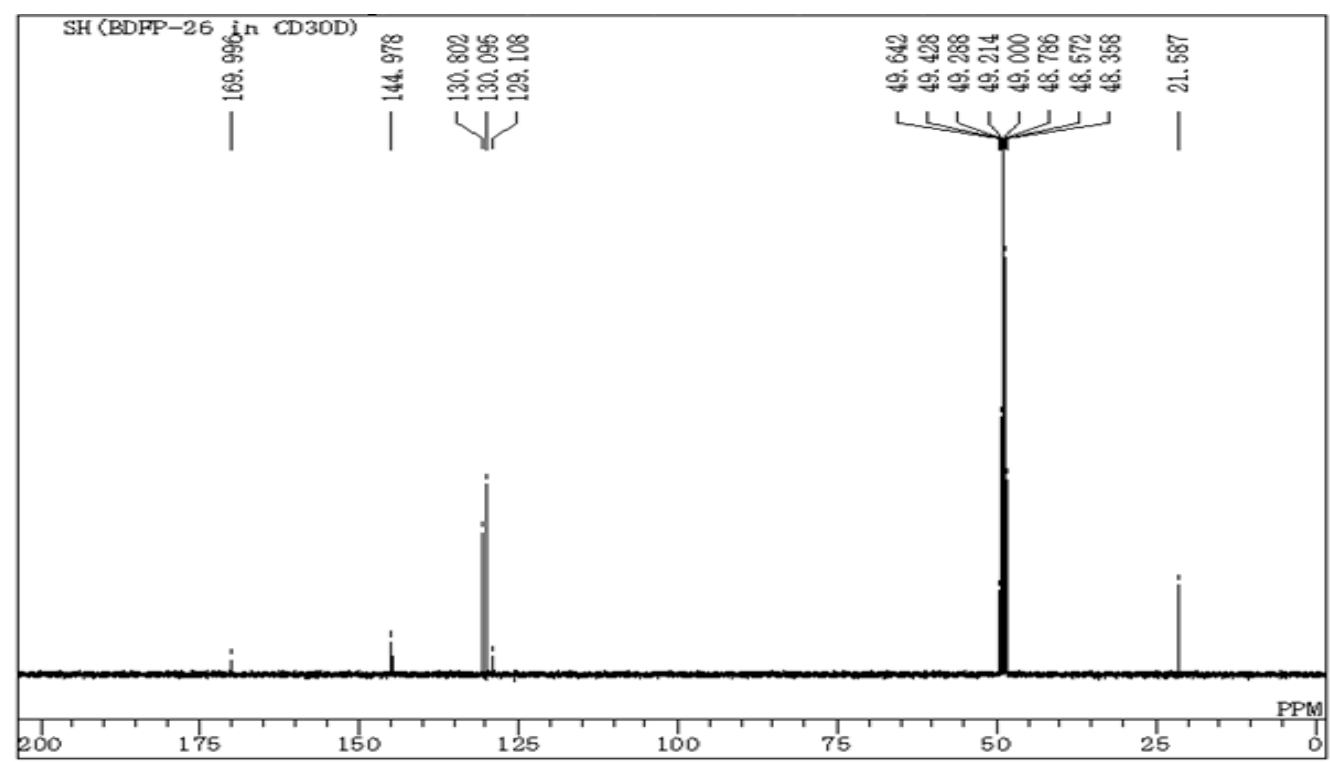

Fig. S3 ${ }^{13} \mathrm{C}$ NMR spectrum of the compound 3

IJNR: https://escipub.com/international-journal-of-nanoparticle-research/ 10 


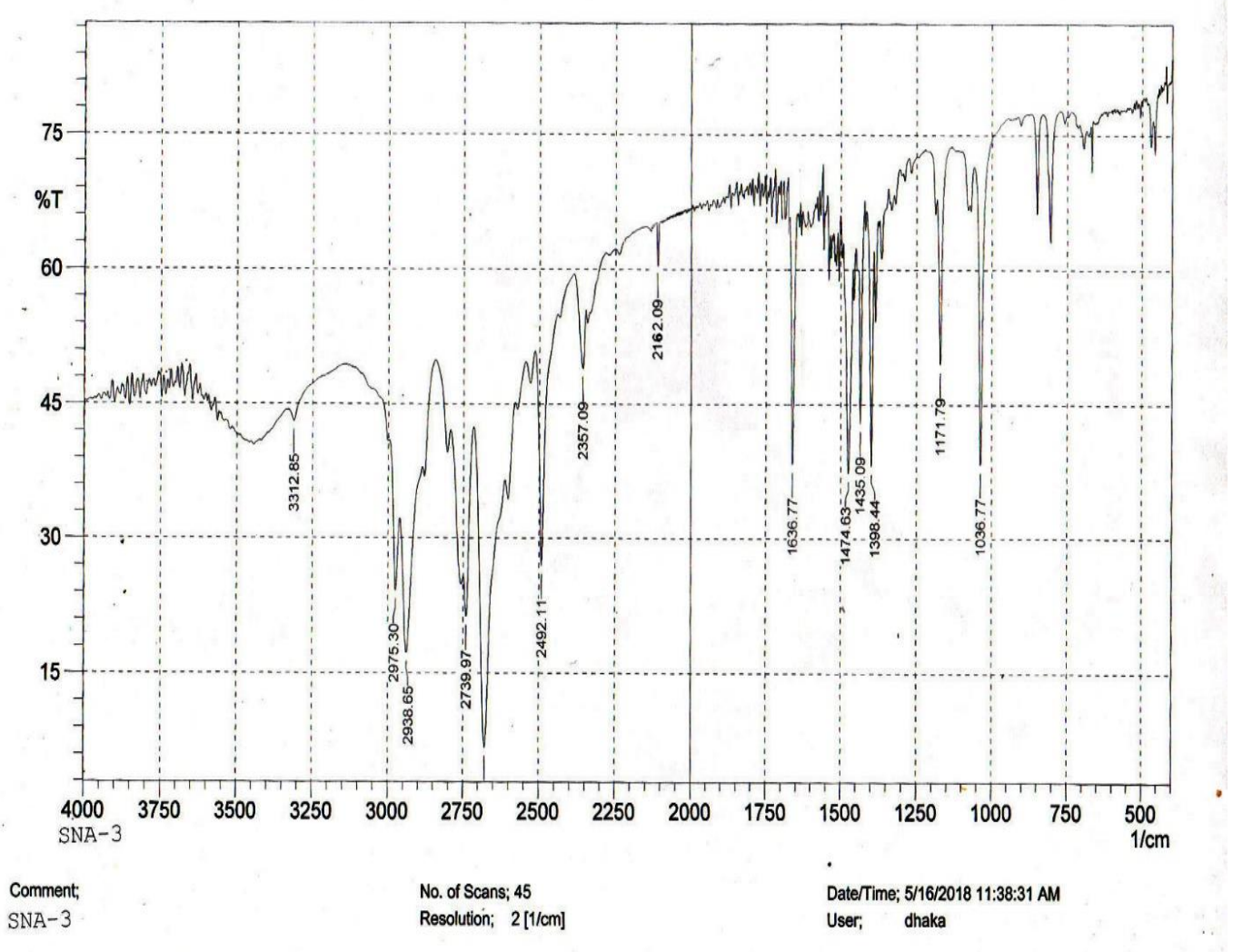

Fig. S4 IR of 1-phenyloct-2-yn-1-one 7

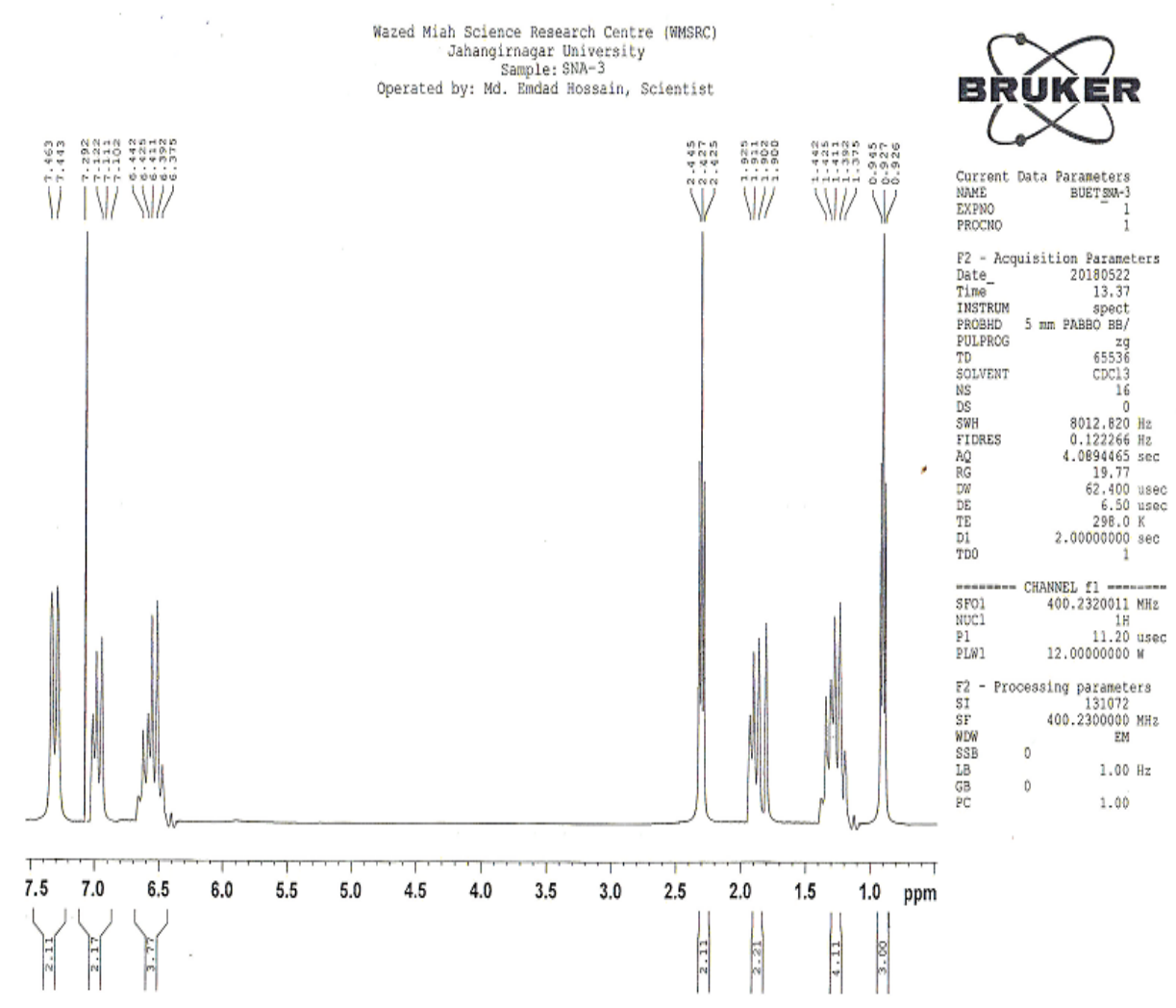

Fig. S5 ${ }^{1} \mathrm{H}$ nmr of 1-phenyloct-2-yn-1-one 7 
Wazed Miah Sclence Research Centre (WMSRC) Jahangirnagar University
Sample: SNA-3,13C

operated by: Nd. Endad Hossain, Bcientist

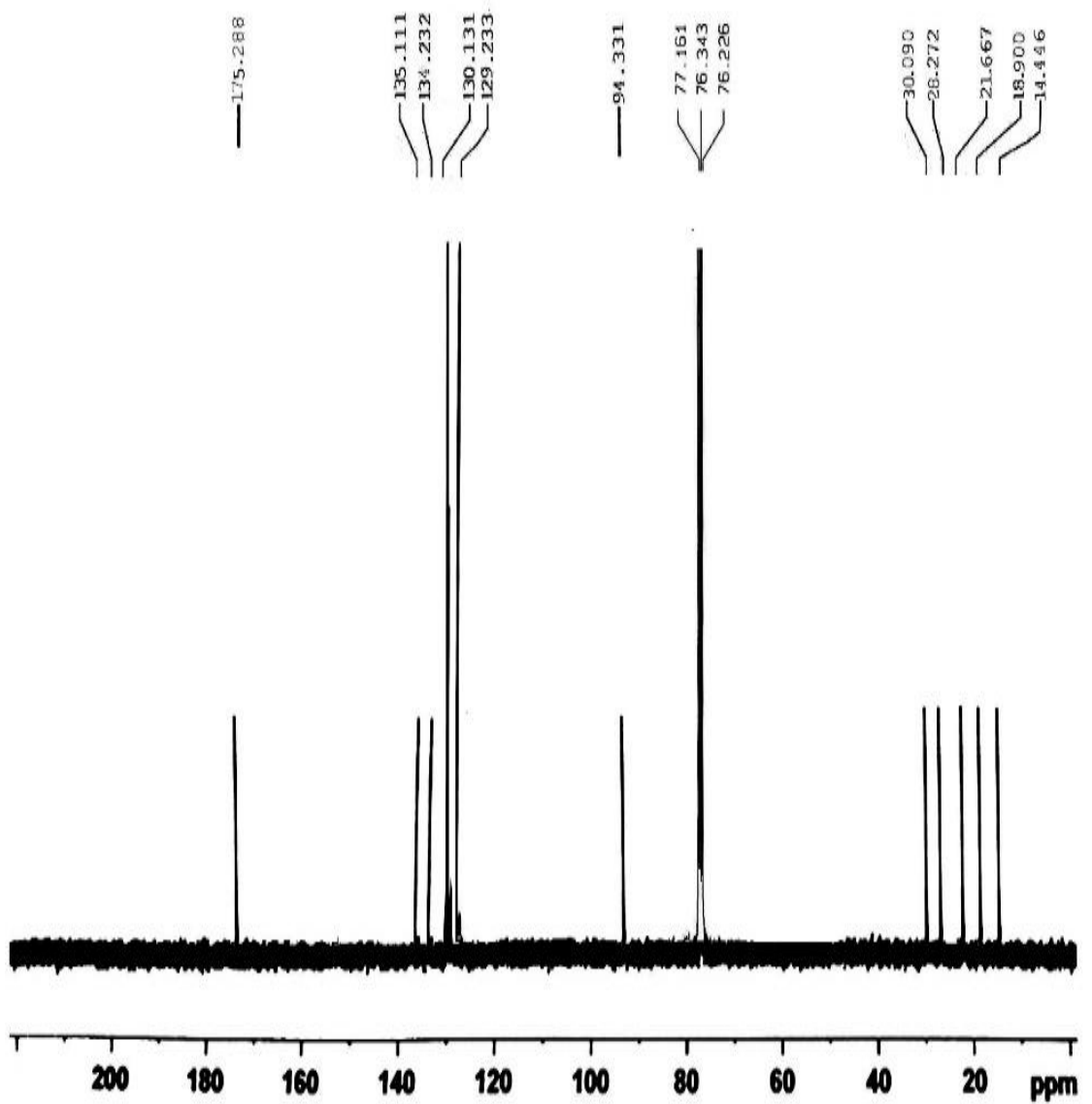

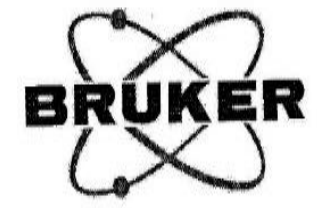

Current Data Parameters NAME BUET SNA-3 EXPNO PROCNO

F2 - Accuisition Parameters $\begin{array}{rr}\text { R2 - Acquisition } & \text { Parate } \\ \text { Date_ } & 11.36\end{array}$ Time 11.36 $5 \mathrm{~mm}$ PABBO BB POLPROG $2 \mathrm{q}$ 29
PULPROG $\begin{array}{ll}\text { TD } & 65536 \\ \text { SOLVENT } & \text { ODC13 }\end{array}$

DS

SWH

PIDRES

$\mathrm{AQ}$
$\mathrm{RG}$

DW

TE

TE

TDO

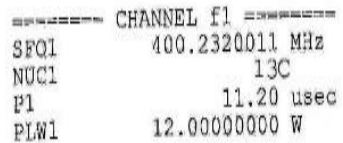

PLW1 $\quad 12.00000000 \mathrm{~W}$

F2 - Processing parameters

$\begin{array}{lcc}\text { F2 - Processing parameters } & \begin{array}{c}131072 \\ \text { SI }\end{array} \\ \text { SF } & 400.2300000 \mathrm{MHz} \\ \text { WDW } & & \text { EM } \\ \text { SSB } & 0 & \\ \text { LB } & & 1,00 \mathrm{~Hz} \\ \text { GB } & 0 & 1.00 \\ \text { PC } & & \end{array}$

Fig. $\mathrm{S} 6{ }^{13} \mathrm{C} \mathrm{nmr}$ of 1-phenyloct-2-yn-1-one 7 